\title{
Hemiarthroplasty compared to total hip arthroplasty for the treatment of femoral neck fractures: a systematic review and meta-analysis
}

Xinbo Li ${ }^{1}$ and Jianning $L \mathrm{LuO}^{2^{*}}$ (1)

\begin{abstract}
Background: Hip replacement is divided into total hip arthroplasty (THA) and hemiarthroplasty (HA); it is still controversial whether to choose THA or HA for femoral neck fractures (FNF). The goal of this study was to review relevant studies in order to determine the HA compared to THA for the treatment of FNF.

Patients and methods: Using appropriate keywords, we identified relevant studies using PubMed, Cochrane, and Embase. Key pertinent sources in the literature were also reviewed, and all articles published through August 2019 were considered for inclusion. For each study, we assessed odds ratios (ORs), mean difference (MD), and 95\% confidence interval $(95 \% \mathrm{Cl})$ to assess and synthesize outcomes.

Results: We included 19 studies with a total of 413,140 patients in the HA group and 44973 in the THA group. The blood loss, surgery time, and dislocation were all significantly decreased in the HA group than the THA group. The length of hospital, pneumonia, and renal failure were significant increased in the HA group than THA group. There has no significant difference of complication, mortality, reoperation, infection, pulmonary embolism, and myocardial infarct between the two groups.

Conclusion: HA has favor in decrease blood loss and surgery time. THA has favor in decrease the length of hospital, the incidence of pneumonia and renal failure. For the selection of surgical methods for femoral neck fracture in the elderly, we should consider several aspects, such as the age of the patient, whether there is osteoporosis, the type of femoral neck fracture, the preoperative reduction situation, and the needs of the patient and his family for the postoperative situation.
\end{abstract}

Keyword: Hemiarthroplasty, Total hip arthroplasty, Femoral neck fractures, Meta-analysis

\footnotetext{
* Correspondence: yyljn20201001@163.com

${ }^{2}$ Trauma Orthopedics Ward 2, Ningbo No. 6 Hospital, No. 1059, Zhongshan East Road, Dongliu Street, Yinzhou District, Ningbo City 315040, Zhejiang Province, China

Full list of author information is available at the end of the article
}

(c) The Author(s). 2021 Open Access This article is licensed under a Creative Commons Attribution 4.0 International License, which permits use, sharing, adaptation, distribution and reproduction in any medium or format, as long as you give appropriate credit to the original author(s) and the source, provide a link to the Creative Commons licence, and indicate if changes were made. The images or other third party material in this article are included in the article's Creative Commons licence, unless indicated otherwise in a credit line to the material. If material is not included in the article's Creative Commons licence and your intended use is not permitted by statutory regulation or exceeds the permitted use, you will need to obtain permission directly from the copyright holder. To view a copy of this licence, visit http://creativecommons.org/licenses/by/4.0/. The Creative Commons Public Domain Dedication waiver (http://creativecommons.org/publicdomain/zero/1.0/) applies to the data made available in this article, unless otherwise stated in a credit line to the data. 


\section{Introduction}

FNF accounts for about $3.6 \%$ of adult fractures, which is one of the more common fractures in the body. FNF is more common in elderly patients, generally refers to the fracture in the part of the femoral head down to the base of the femoral neck. Garden classification is often adopted for FNF in the elderly, type I and type II, because no displacement or displacement of fracture end to a lesser degree, damage degree of fracture is lesser, belongs to the stable fractures. Type III and type IV due to shifting more of fracture end, fracture damage is bigger, belongs to the unstable fractures. The clinical features and fracture healing of the four types has presented in Table 1 [1-3].

FNF in older patients are not stable fractures (Garden III, IV), accompanied with the complications: the serious situation of displacement fracture, the longer time of conservative treatment in bed, pulmonary embolism, falling pneumonia, lower limb thrombosis, bone nonunion, urinary system infection, and so on. At the same time, the conservative treatment of fracture carries the bad counterpoint to the line, high rate of fracture malunion, physical disability, ischemic necrosis of femoral head; so still need hip replacement later. Hip replacement is divided into THA and HA, THA requires replacement of femoral head and acetabulum. Compared with THA, HA only replaces the femoral head, which requires less technical requirements for the surgeon. The advantages of HA including less surgical trauma, less blood loss, and low economic cost; the disadvantages are high incidence of postoperative pain and further wear of untreated acetabular cartilage. Therefore, it is still controversial whether to choose THA or HA for specific patients $[4,5]$.

The aim of this study was to perform a meta-analysis of all available literature to obtain updated evidence to eradicate the HA versus THA for the treatment of FNF and to provide a basis for the selection of clinical treatment.

\section{Methods}

\section{Search strategy}

To identify studies pertaining to the clinical results about HA versus THA in the treatment of FNF, we reviewed the Cochrane, Pubmed, Embase databases for relevant articles published through August 2019. We also reviewed the references of all identified articles to identify additional studies. Search terms were as follows: femoral neck fracture, femoral fracture, fracture of the femoral neck, FNF, hemihip arthroplasty, hemiarthroplasty, HA, THA, total hip arthroplasty, total hip replacement, total hip joint replacement. These terms were used in combination with "AND" or "OR". This literature review was performed independently by two investigators, with a third resolving any disputes as needed.

Following the PICOS (Participants, Interventions, Comparisons, Outcomes and Study design) principle, the key search terms included (P) patients with FNF; (I) patients were treated by HA or THA; $(\mathrm{C} / \mathrm{O})$ the outcomes including complication, blood loss, surgery time, length of hospital, mortality, dislocation, reoperation, infection, pneumonia, pulmonary embolism, myocardial infarct, renal failure; (S) RTC, cohort study, or casecontrol study.

\section{Study selection criteria}

Included studies met the following criteria: (1) randomized controlled trials, cohort studies or case-control studies; (2) the research objects are patients with FNF; (3) the treatment of experiment group is HA, the inventions of control groups are THA; (4) English or Chinese language.

Table 1 The Garden classification of FNF

\begin{tabular}{|c|c|c|}
\hline $\begin{array}{l}\text { Garden } \\
\text { classification } \\
\text { of FNF }\end{array}$ & Clinical features of the fracture & Fracture healing \\
\hline Type I & $\begin{array}{l}\text { The fracture line does not run through the entire femoral neck, } \\
\text { part of the bone is connected, and the broken end of the fracture } \\
\text { is not displaced. }\end{array}$ & $\begin{array}{l}\text { There is still a certain blood supply near the broken end, and the } \\
\text { fracture is easy to heal. }\end{array}$ \\
\hline Type ॥ & $\begin{array}{l}\text { Complete fracture with fracture line running through the neck of } \\
\text { femur without displacement of the broken end. }\end{array}$ & $\begin{array}{l}\text { Even if the fracture line is in good alignment under the femoral } \\
\text { head, the possibility of fracture healing is higher, but the } \\
\text { probability of long-term femoral head necrosis is increased. } \\
\text { However, the fracture of the middle or basal part of the femoral } \\
\text { neck is easy to heal, the femoral head blood supply is good, and } \\
\text { the avascular necrosis of the femoral head is low. }\end{array}$ \\
\hline Type III & $\begin{array}{l}\text { Partial displacement of fracture, mostly distal upward } \\
\text { displacement, or distal lower Angle embedded into the proximal } \\
\text { folded end of the section. }\end{array}$ & $\begin{array}{l}\text { It is an unstable fracture, postoperative fracture healing rate is } \\
\text { not high. }\end{array}$ \\
\hline Type IV & $\begin{array}{l}\text { Fracture completely shift, femoral neck appear obvious outward } \\
\text { turning up, the hip joint capsule and synovial suffered severe } \\
\text { damage, femoral head poor blood supply }\end{array}$ & Fracture is not easy to heal, easy femoral head necrosis. \\
\hline
\end{tabular}


Studies were excluded for meeting the following criteria: (1) repeat articles or results; (2) clear data errors; (3) case reports, case-control studies, theoretical research, conference reports, systematic reviews, metaanalyses, and other forms of research or comment not designed in a randomized controlled manner; (4) irrelevant outcomes; (5) has no control group.

Two investigators independently determined whether studies met with inclusion criteria, with a third resolving any disputes as needed.

\section{Data extraction and quality assessment}

For each included study, two categories of information were extracted: basic information and primary study outcomes. Basic information relevant to this meta-analysis included author names, year of publication, sample size, age, gender, and study design. Primary clinical outcomes relevant to this analysis included: complication, blood loss, surgery time, length of hospital, mortality, dislocation, reoperation, infection, pneumonia, pulmonary embolism, myocardial infarct, renal failure. This data extraction was performed independently by two investigators, with a third resolving any disputes as needed.

\section{Statistical analysis}

STATA v10.0 (TX, USA) was used for all analyses. Heterogeneity in study results was assessed using chisquared and $I^{2}$ tests and appropriate analysis models (fixed-effect or random-effect) were determined. A chisquared $P \leq 0.05$ and an $I^{2}>50 \%$ indicated high heterogeneity and a random-effects model was used in this case. A chi-squared $P>0.05$ and an $I^{2} \leq 50 \%$ indicated acceptable heterogeneity and a fixed-effects model were instead used. Continuous variables are given as means \pm standard deviations and were compared on the basis of mean difference (MD), while categorical data is given as percentages and compared based on relative risk (RR)/ odds ratios (ORs). MD and 95\% CI were used to analyze blood loss, surgery time, and length of hospital. The other indexes were analyzed by RR and 95\% CI.

\section{Results}

\section{Overview of included studies}

We reviewed a total of 985 articles identified by our initial keyword search, of which 864 were excluded following title/abstract review. The PRISMA 2009 flow diagram has presented the detailed literature screening process. The PRISMA 2009 checklist has presented the specific framework and content of the article. The remaining 121 articles were subject to a complete fulltext assessment, leading to 102 articles being excluded for failing to meet study inclusion criteria. Reasons for exclusion of these studies included theoretical research (11), no clinical outcomes (54), repeated articles (3), case reports (8), and only one group (26). We ultimately identified a total of 19 studies [6-24] that met with inclusion criteria for this meta-analysis, incorporating 413, 140 patients in the HA group and 44,973 in the THA group. Study selection is outlined in Fig. 1.

Table 2 summarizes the basic information for each study, including author names, year of publication, sample, age, gender, and study design. The main age of all included studies was over 58 years old.

\section{Complication}

In total, 11 studies were included, containing 38,129 patients in the HA group and 11,633 patients in the THA group. Based on a chi-squared $P=0.000<0.05$ and an $I^{2}$ $=73.3 \%>50 \%$, a random-effects model was chosen to assess complication. The incidence of complication has no significant difference between the two groups (RR, 1.18; 95\% CI, $1.00 \sim 1.39$ ). The results were presented in Fig. 2.

\section{Blood loss}

In total, 5 studies were included, containing 254 patients in the HA group and 251 patients in the THA group. Based on a chi-squared $P=0.002<0.05$ and an $I^{2}=76.7 \%$ $>50 \%$, a random-effects model was chosen to assess blood loss. The blood loss was significant lower in the HA group than the THA group (WMD, -45.63 ; 95\% CI, -74.50 -16.76). The results were presented in Fig. 3.

\section{Surgery time}

In total, 10 studies were included, containing 32,731 patients in the HA group and 6731 patients in the THA group. Based on a chi-squared $P=0.000<0.05$ and an $I^{2}=99.9 \%>50 \%$, a random-effects model was chosen to assess surgery time. The surgery time was significantly decreased in the HA group than THA group (WMD, -12.28 ; 95\% CI, $-13.07 \sim-11.49$ ). The results were presented in Fig. 4.

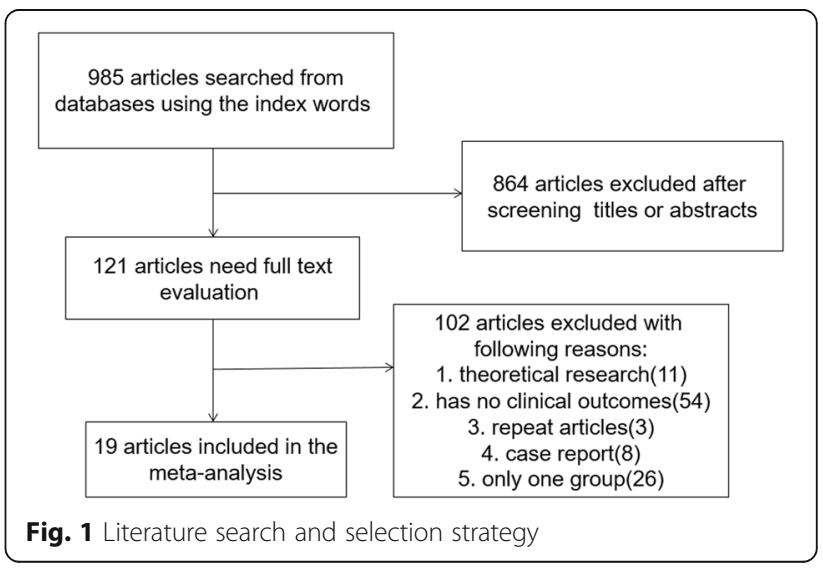


Table 2 The basic characteristics description of included studies

\begin{tabular}{|c|c|c|c|c|c|c|c|}
\hline \multirow[t]{2}{*}{ Study } & \multicolumn{2}{|c|}{ No. of patients } & \multicolumn{2}{|l|}{ Age } & \multicolumn{2}{|l|}{ Gender } & \multirow[t]{2}{*}{ Study design } \\
\hline & HA & THA & $\mathrm{HA}$ & THA & HA & THA & \\
\hline Sebastian Mukka 2019 [6] & 118 & 61 & & & & & Prospective, single-center cohort study \\
\hline Ghazi Chammout 2019 [7] & 60 & 60 & 86 & 85 & $45 \mathrm{~F}$ & $45 \mathrm{~F}$ & $\mathrm{RCT}$ \\
\hline Skender Ukaj 2019 [8] & 47 & 47 & 77.64 & 78.11 & $15 F$ & $24 \mathrm{~F}$ & $\begin{array}{l}\text { Randomized, prospective, comparative interventional } \\
\text { single-blinded study }\end{array}$ \\
\hline Bheeshma Ravi 2019 [9] & 2689 & 2689 & 79 & 79 & $1901 \mathrm{~F}$ & $1901 \mathrm{~F}$ & A population-based, retrospective cohort study \\
\hline Bheeshma Ravi 2019 [9] & 26408 & 2713 & 83 & 79 & $19084 \mathrm{~F}$ & $1916 \mathrm{~F}$ & A population-based, retrospective cohort study \\
\hline Scott M Eskildsen 2018 [10] & 275439 & 26017 & & & & & $\begin{array}{l}\text { A national for-fee database of Medicare patient procedure } \\
\text { and diagnosis records from } 2005 \text { to } 2012\end{array}$ \\
\hline Joey P. Johnson 2019 [11] & 33660 & 9909 & 58.5 & 58.2 & $20533 F$ & $6480 \mathrm{~F}$ & Cohort study \\
\hline Fatih Cansah Barıshan 2018 [12] & 22 & 16 & 76.9 & 73.6 & $14 \mathrm{~F}$ & $11 \mathrm{~F}$ & Case-control \\
\hline B. Boukebous 2017 [13] & 101 & 98 & 83.3 & 77.8 & $28 \mathrm{M}$ & $28 \mathrm{M}$ & Retrospective Case-control study \\
\hline M. FUCHS 2017 [14] & 70 & 91 & 81.7 & 76.4 & & & Cohort study \\
\hline Yong Tae Kim 2018 [15] & 84 & 84 & 72.9 & 73.1 & $27 \mathrm{M}$ & $26 \mathrm{M}$ & Retrospective cohort study \\
\hline Stefan Bartels 2017 [16] & 1030 & 572 & 64.9 & 63.7 & $672 \mathrm{~F}$ & $412 \mathrm{~F}$ & Cohort study \\
\hline Zhong Wang 2017 [17] & 69142 & 1100 & $18115 \mathrm{M}$ & $304 \mathrm{M}$ & & & Cohort study \\
\hline Emmanouil Liodakis 2016 [18] & 3192 & 866 & 81.9 & 72.9 & $952 \mathrm{M}$ & $275 \mathrm{M}$ & Case-control \\
\hline Christopher P. Miller 2014 [19] & 783 & 419 & $544 \mathrm{~F}$ & $250 \mathrm{~F}$ & & & Cohort study \\
\hline Kyung-Soon Park 2013 [20] & 41 & 44 & 71.6 & 73.6 & $14 \mathrm{M}$ & $11 \mathrm{M}$ & Case-control \\
\hline YUE-JU LIU 2012 [21] & 55 & 60 & & & & & Case-control \\
\hline Carl Johan Hedbeck 2011 [22] & 60 & 60 & 80.7 & 80.5 & $54 \mathrm{~F}$ & $47 \mathrm{~F}$ & $\mathrm{RCT}$ \\
\hline William Macaulay 2008 [23] & 17 & 23 & 82 & 77 & $7 F$ & $14 \mathrm{~F}$ & Case-control \\
\hline James S. Gebhard 1999 [24] & 122 & 44 & 76.2 & 75.2 & & & Case-control \\
\hline
\end{tabular}

\section{Length of hospital}

In total, 7 studies were included, containing 66,099 patients in the HA group and 16,351 patients in the THA group. Based on a chi-squared $P=0.000<0.05$ and an $I^{2}=100.0 \%>50 \%$, a random-effects model was chosen to assess the length of hospital. The length of hospital was significantly longer in the HA group than the THA group (WMD, 0.47; 95\% CI, $0.20 \sim 0.74$ ). The results were presented in Fig. 5.

\section{Mortality}

In total, 10 studies were included, containing 35,242 patients in the HA group and 11,005 patients in the THA group. Based on a chi-squared $P=0.000<0.05$ and an $I^{2}=87.2 \%>50 \%$, a random-effects model was chosen to assess mortality. The mortality has no significant difference between the two groups (RR, 1.79; 95\% CI, 0.79 3.29). The results were presented in Fig. 6.

\section{The other indexes}

The incidence of reoperation ( $\mathrm{RR}, 1.319 ; 95 \% \mathrm{CI}, 0.710$ 2.448), infection (RR, 1.037; 95\% CI, $0.760 \sim 1.416$ ), pulmonary embolism (RR, 1.160, 95\% CI, $0.803 \sim 1.676)$, myocardial infarct (RR, 1.459; 95\% CI, $0.988 \sim 2.156$ ) has no significant difference between the two groups.
The incidence of dislocation was significant decrease in the HA group than the THA group (RR, 0.536; 95\% CI, $0.502 \sim 0.573)$. The incidence of pneumonia (RR, 1.511; 95\% CI, $1.275 \sim 1.791$ ) and renal failure (RR, 1.493; 95\% CI, $1.188 \sim 1.876)$ were significantly higher in the HA group than the THA group. All the above results were presented in Table 3.

\section{Quality and bias assessment}

An assessment of study quality and risk of bias was performed using multiple complementary methods including funnel plots, Begg's and Mazumdar's rank test, and Egger's test. There was clear symmetry in the log RR funnel plot for dislocation for these studies, suggesting a low publication bias risk (Fig. 7). The results of Begg's and Mazumdar's rank test $(Z=1.25, p=0.210)$ and Egger's test $(P=0.072)$ both suggested that there was not any significant risk of bias among study results.

\section{Discussion}

FNF mostly occurs in middle-aged and elderly people and is associated with decreased bone quality due to osteoporosis. Fractures can occur when a mild twisting force is experienced, most often as a result of a fall while walking or slipping. When falling, as a result of the body 


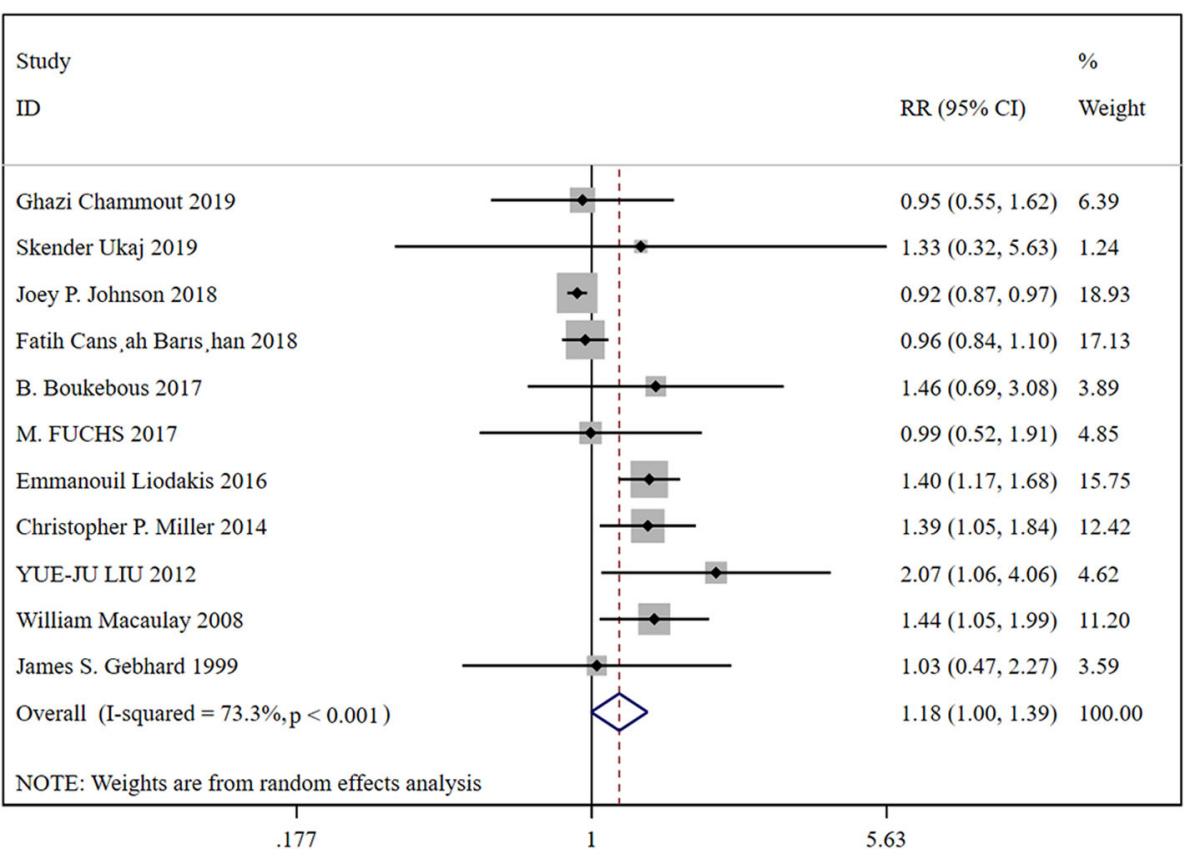

Fig. 2 Forest plot for the complication

torsion, indirect transmission of violence resulting in FNF. FNF are less common in adolescents, and when they do occur, they often require significant violence and are often unstable. The two main treatments for FNF are internal fixation and joint replacement. The physical characteristics of the elderly are relatively low-stress response ability to trauma, relatively weak immune suppression, and defense function. Fracture healing in the elderly is relatively slow, and most of the elderly combined with cardiopulmonary and brain diseases. Therefore, elderly patients who are bedridden for a long time are more likely to suffer from serious complications, such as some diseases such as urinary tract infection, lung inflammation, and bedsore. Elderly patients are in bed for a long time, and due to the factors of fracture, the disease existing before the fracture is more prone to relapse, leading to a high disability rate and mortality rate.

Currently, there are many surgical methods to treat FNF, but generally speaking, it is generally agreed that

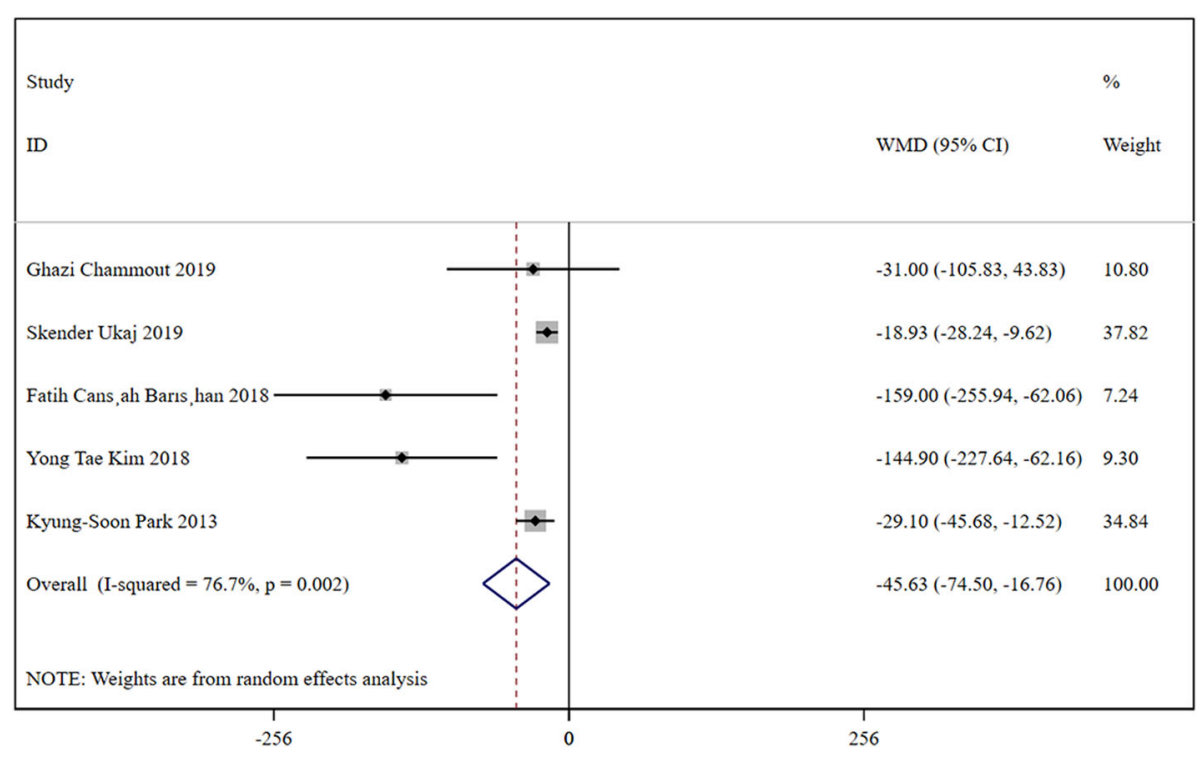

Fig. 3 Forest plot for the blood loss 


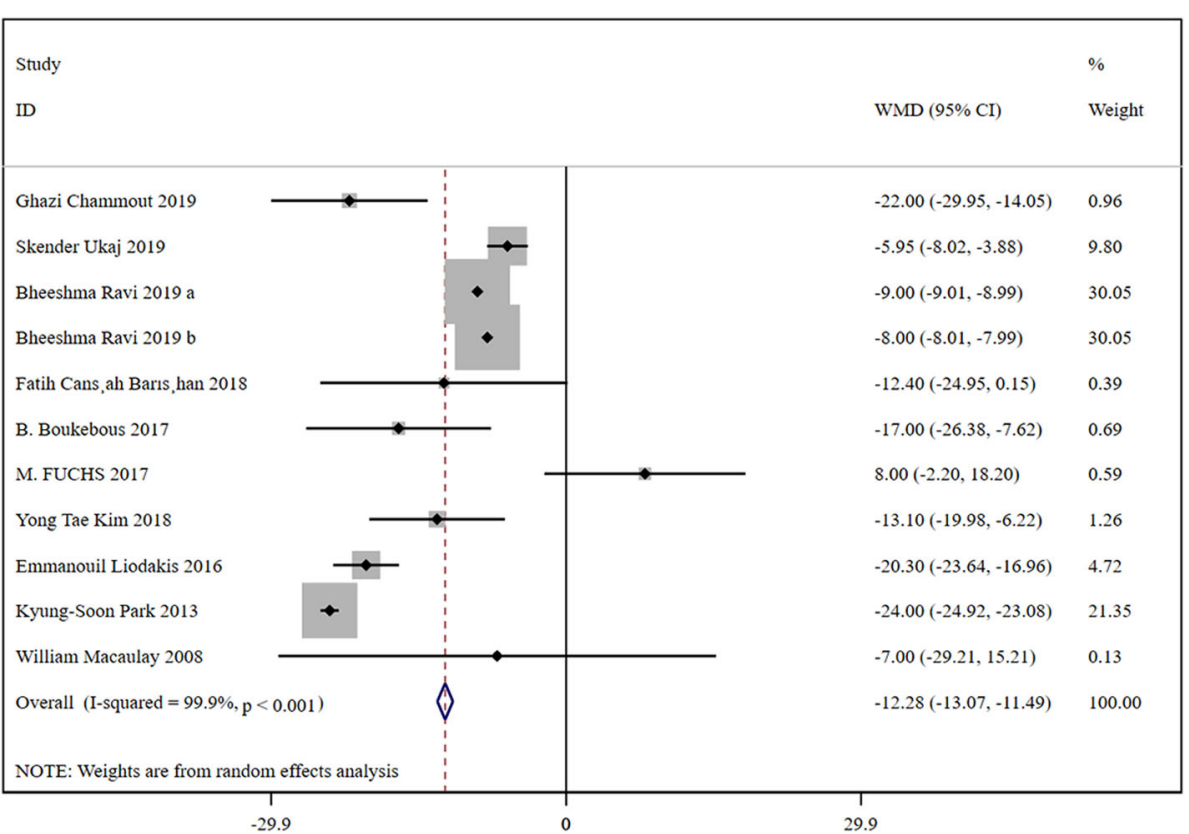

Fig. 4 Forest plot for the surgery time

the better method is artificial joint replacement. Currently, HA and THA are widely used, and both advantages and disadvantages exist in clinical practice. Hip replacement can significantly reduce the incidence of postoperative joint pain in patients, and because of the patient's early weight-bearing walking, it is very important to maintain the muscle strength of the affected limb and restore good overall health. The advantages and disadvantages were discussed in the following aspects.

Firstly, it is about the risk of operation. Compared with HA, THA has many disadvantages, such as complex, large trauma, long operation time, and more intraoperative and postoperative bleeding. The advantages of HA include less trauma, short operation duration, small

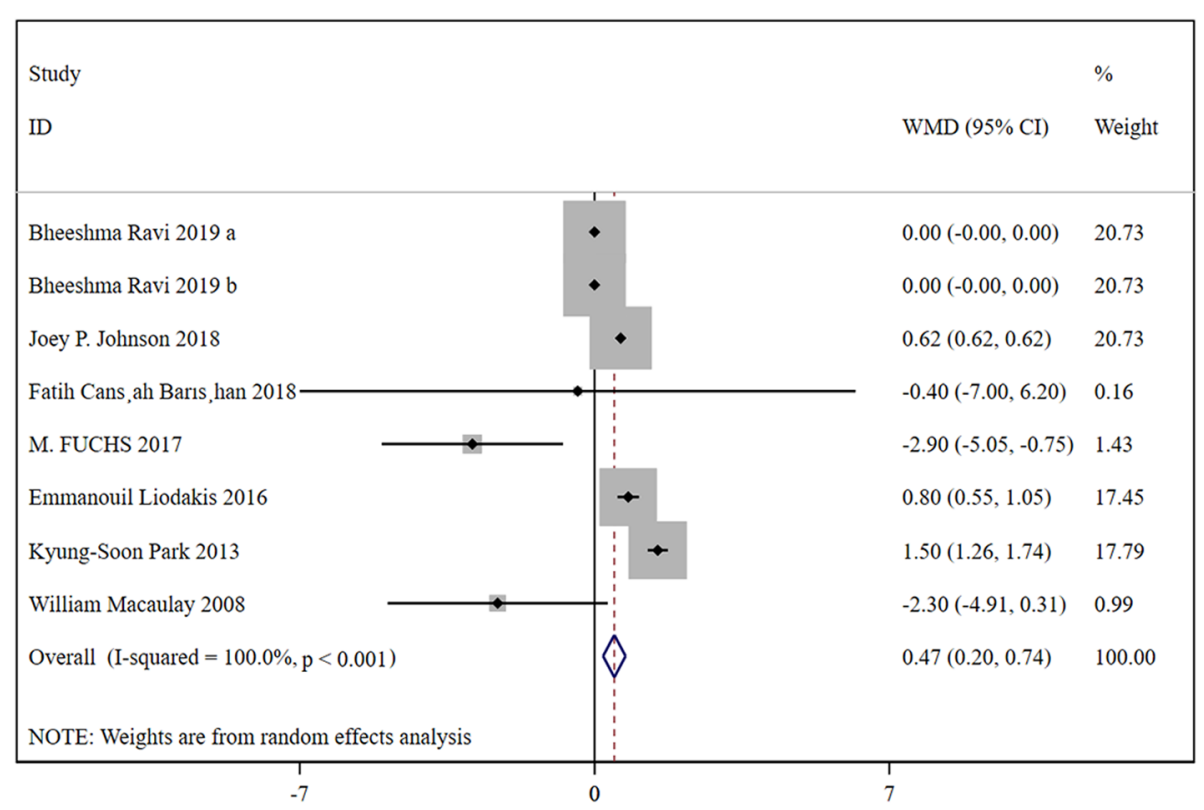

Fig. 5 Forest plot for the length of hospital 


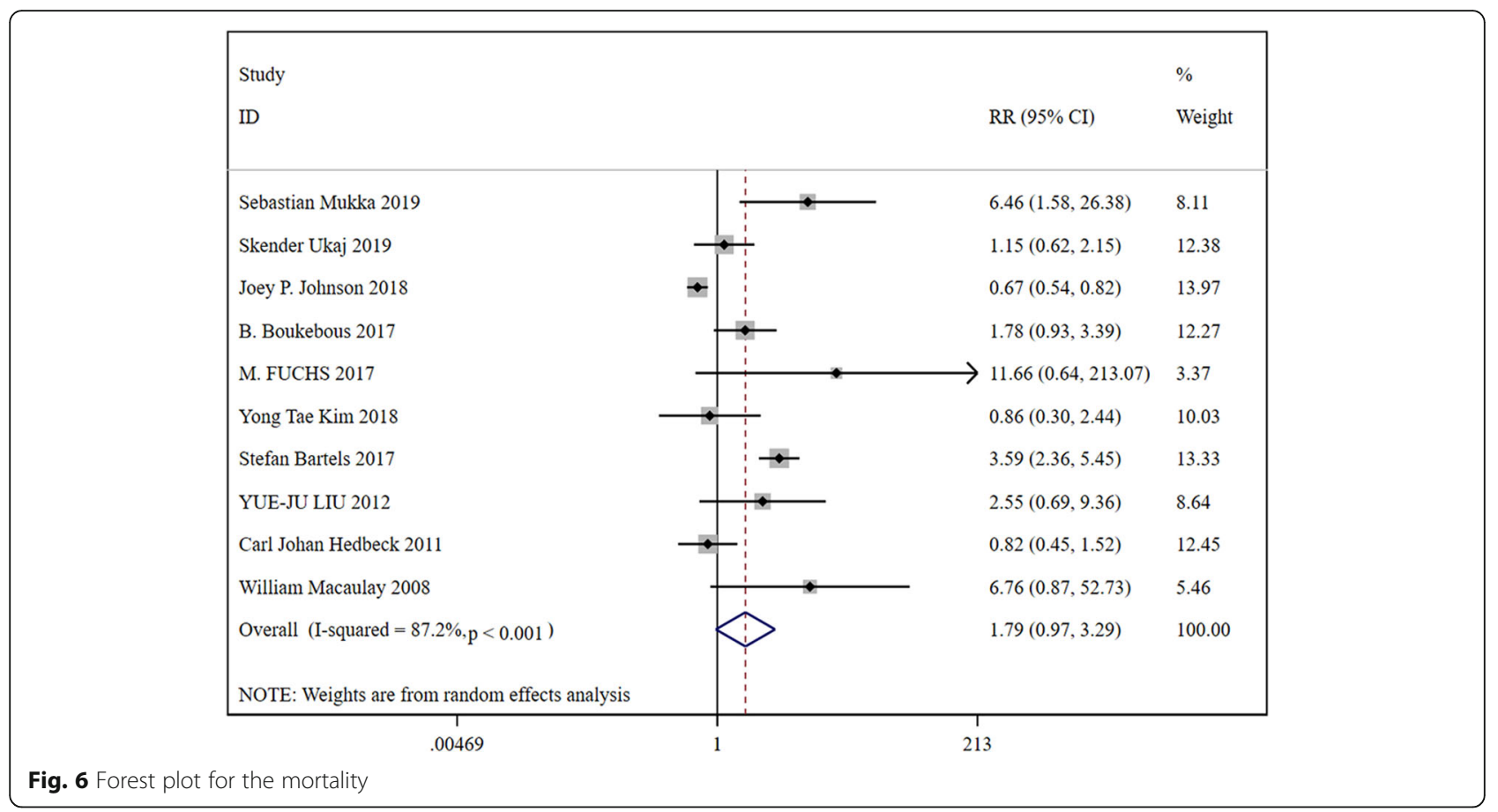

blood loss, simple operation compared with total hip, and high surgical safety compared with THA. However, with the development of all aspects of science and technology, the surgical risk of THA is becoming less and less, because the differences between the two surgical methods in many aspects become smaller. However, the surgical risk of THA is still high in the treatment of elderly patients with medical complications. In our study, we found that the blood loss (WMD, -45.63 ; 95\% CI, $-74.50 \sim-16.76$ ), surgery time (WMD, -12.28 ; 95\% CI, $-13.07 \sim-11.49)$ were all significant decreased in the HA group than the THA group. However, the length of hospital was significantly longer in the HA group than the THA group (WMD, 0.47; 95\% CI, $0.20 \sim 0.74$ ). The mortality has no significant difference between the two groups (RR, 1.79; 95\% CI, $0.79 \sim 3.29$ ).
Secondly, it is about the reoperation. The rate of reoperation is also an important factor affecting the choice of hip arthroplasty. Dislocation of prosthesis, wear of acetabular cartilage, and sterility of artificial prosthesis are the main causes of reoperation. After a hip replacement, the joint is removed and replaced with a new one. The procedure is relatively complex and technically demanding. This operation is definitely not a simple "old for new" process. It also takes into account the differences in surgical approaches used by surgeons during the first operation, the changes in anatomy and surrounding soft tissue, and the bone defects caused by the first artificial prosthesis. Therefore, for patients, it is necessary to give them good satisfaction and reduce the probability of reoperation. In our study, we found that the incidence of reoperation $(\mathrm{RR}, 1.319 ; 95 \% \mathrm{CI}, 0.710 \sim 2.448)$ has no

Table 3 The results of meta-analysis

\begin{tabular}{|c|c|c|c|c|c|c|c|}
\hline \multirow[t]{2}{*}{ Index } & \multirow{2}{*}{$\begin{array}{l}N \text { (case/ } \\
\text { control) }\end{array}$} & \multirow[t]{2}{*}{$R R(95 \% \mathrm{Cl})$} & \multirow[t]{2}{*}{$P^{*}$} & \multirow[t]{2}{*}{$I^{2}$} & \multirow[t]{2}{*}{$P^{\#}$} & \multicolumn{2}{|l|}{$P$ value } \\
\hline & & & & & & Begg's & Egger's \\
\hline Dislocation & $374242 / 33026$ & $0.536(0.502,0.573)$ & 0.098 & $35.5 \%$ & 0.000 & 0.951 & 0.032 \\
\hline Reoperation & $378085 / 34168$ & $1.319(0.710,2.448)$ & 0.000 & $91.9 \%$ & 0.381 & 0.602 & 0.257 \\
\hline Infection & $341683 / 42513$ & $1.037(0.760,1.416)$ & 0.000 & $82.4 \%$ & 0.819 & 0.283 & 0.113 \\
\hline Pneumonia & $32621 / 6546$ & $1.511(1.275,1.791)$ & 0.415 & $2.3 \%$ & 0.000 & 0.754 & 0.457 \\
\hline Pulmonary embolism & $33241 / 6877$ & $1.160(0.803,1.676)$ & 0.394 & $4.6 \%$ & 0.429 & 0.386 & 0.154 \\
\hline Myocardial infarct & $32458 / 6458$ & $1.459(0.988,2.156)$ & 0.740 & $0.0 \%$ & 0.058 & 0.368 & 0.150 \\
\hline Renal/kidney failure & $32441 / 6435$ & $1.493(1.188,1.876)$ & 0.730 & $0.0 \%$ & 0.001 & 0.133 & 0.173 \\
\hline
\end{tabular}

${ }^{*} P$ value of heterogeneity chi-squared

${ }^{\#} P$ value of pooled statistic 


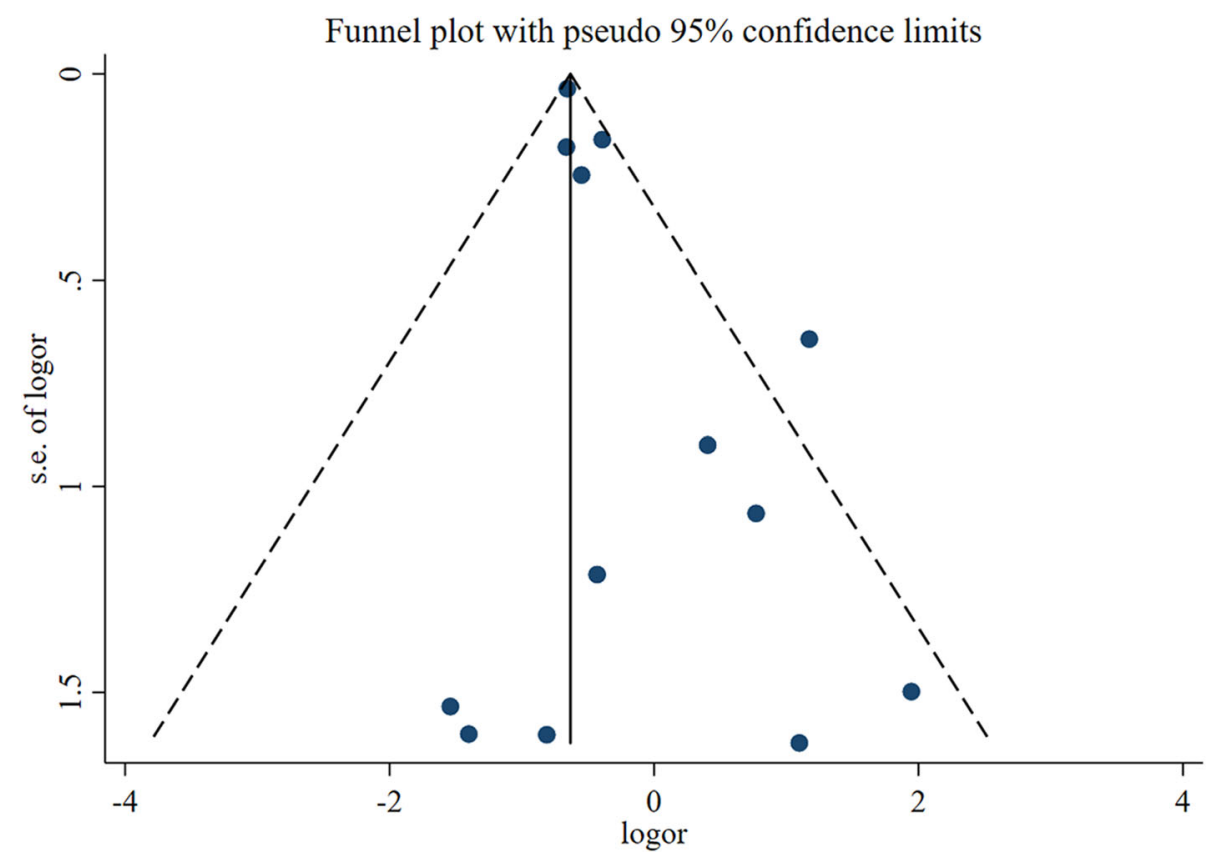

Fig. 7 Funnel plot analysis of included studies

significant difference between the two groups. The incidence of dislocation was significant decrease in the HA group than THA group (RR, 0.536; 95\% CI, 0.502 0.573).

Third, it is about the complications. The elderly, as a group with a high incidence of FNF, account for about 46 percent of fractures in the elderly (4\%). Elderly people suffer from many basic diseases, weakened constitution, decreased organ function, and surgical trauma, so the postoperative recovery is slow and the postoperative bed rest time is long. If the risk of postoperative complications increases, it will have a certain impact on the efficacy and prognosis of the operation. The incidence of complication has no significant difference between the two groups (RR, 1.18; 95\% CI, $1.00 \sim 1.39$ ). The infection (RR, 1.037; 95\% CI: $0.760 \sim 1.416)$, pulmonary embolism (RR, 1.160; 95\% CI, $0.803 \sim 1.676$ ), myocardial infarct (RR, 1.459; 95\% CI, $0.988 \sim 2.156$ ) has no significant difference between the two groups. The incidence of pneumonia (RR, 1.511; 95\% CI, $1.275 \sim 1.791$ ) and renal failure (RR, 1.493; 95\% CI, $1.188 \sim 1.876)$ were significantly higher in the HA group than the THA group.

However, there are certain limitations to the present analysis, which are as follows: (1) the limited number of included studies; (2) individual studies had variations in exclusion/inclusion criteria; (3) surgical skills varied between studies; (4) the severity of FNF in patients varied between studies; (5) the background diseases of patients were various between studies; (6) some studies were not high-quality; (7) pooled data were analyzed, as individual patient data was not available, precluding more in-depth analyses.

\section{Conclusion}

In a word, we found that HA has favor in decrease blood loss and surgery time and THA has favor in decrease the length of hospital, the incidence of pneumonia and renal failure. For the selection of surgical methods for femoral neck fracture in the elderly, we should consider several aspects, such as the age of the patient, whether there is osteoporosis, the type of femoral neck fracture, the preoperative reduction situation, and the needs of the patient and his family for the postoperative situation.

\section{Supplementary Information}

The online version contains supplementary material available at https://doi. org/10.1186/s13018-020-02186-4.

\section{Additional file 1.}

Additional file 2.

Abbreviations

HA: Hemiarthroplasty; THA: Total hip arthroplasty; FNF: Femoral neck fractures; ORs: Odds ratios; MD: Mean difference; 95\% Cl: 95\% confidence interval

\section{Acknowledgements}

Not applicable.

Authors' contributions

$J L$ and $X L$ designed this study and screened the literature; $J$ extracted data used in the final meta-analysis; and $\mathrm{XL}$ completed the data analysis of this study. All authors participated in writing and approved the final manuscript. 


\section{Funding}

Not applicable.

\section{Availability of data and materials}

The datasets used and/or analyzed during the current study are available from the corresponding author on reasonable request.

\section{Ethics approval and consent to participate}

Not applicable.

\section{Consent for publication}

Not applicable.

\section{Competing interests}

The authors declare that they have no competing interests.

\section{Author details}

'Trauma Orthopedics Ward 1, Ningbo No. 6 Hospital, No. 1059, Zhongshan East Road, Dongliu Street, Yinzhou District, Ningbo City 315040, Zhejiang Province, China. ${ }^{2}$ Trauma Orthopedics Ward 2, Ningbo No. 6 Hospital, No. 1059, Zhongshan East Road, Dongliu Street, Yinzhou District, Ningbo City 315040, Zhejiang Province, China.

Received: 15 October 2020 Accepted: 25 December 2020 Published online: 03 March 2021

\section{References}

1. Guyen O. Hemiarthroplasty or total hip arthroplasty in recent femoral neck fractures? Orthop Traumatol Surg Res. 2019;105(1):95-101.

2. Florschutz AV, Langford JR, Haidukewych GJ, Koval KJ. Femoral neck fractures: current management. J Orthop Trauma. 2015;29(3):121-9.

3. Miller BJ, Callaghan JJ, Cram P, Karam M, Marsh JL, Noiseux NO. Changing trends in the treatment of femoral neck fractures: a review of the American Board of Orthopaedic surgery database. J Bone Joint Surg Am. 2014;96(17): e149.

4. Riggs BL, Melton $\sqcup$ 3rd. The worldwide problem of osteoporosis: insights afforded by epidemiology. Bone. 1995;17(5):505-11.

5. Kannan A, Kancherla R, McMahon S, Hawdon G, Soral A, Malhotra R. Arthroplasty options in femoral-neck fracture: answers from the national registries. Int Orthop. 2012;36(1):1-8.

6. Mukka S, Sjöholm P, Chammout G, Kelly-Pettersson P, Sayed-Noor AS, Sköldenberg O. External validity of the HOPE-trial: hemiarthroplasty compared with total hip arthroplasty for displaced femoral neck fractures in octogenarians. JB JS Open Access. 2019;4(2):e0061.

7. Chammout G, Kelly-Pettersson P, Hedbeck CJ, Stark A, Mukka S, Sköldenberg O. HOPE-Trial: hemiarthroplasty compared with total hip arthroplasty for displaced femoral neck fractures in octogenarians: a randomized controlled trial. JB JS Open Access. 2019;4(2):e0059.

8. Ukaj S, Zhuri O, Ukaj F, Podvorica V, Grezda K, Caton J, et al. Dual mobility acetabular cup versus hemiarthroplasty in treatment of displaced femoral neck fractures in elderly patients: comparative study and results at minimum 3-year follow-up. Geriatr Orthop Surg Rehabil. 2019;10: 2151459319848610.

9. Ravi B, Pincus D, Khan H, Wasserstein D, Jenkinson R, Kreder HJ. Comparing complications and costs of total hip arthroplasty and hemiarthroplasty for femoral neck fractures: a propensity score-matched, population-based study. J Bone Joint Surg Am. 2019;101(7):572-9.

10. Eskildsen SM, Kamath GV, Del Gaizo DJ. Age matters when comparing hemiarthroplasty and total hip arthroplasty for femoral neck fractures in Medicare patients. Hip Int. 2019;29(6):674-9.

11. Johnson JP, Kleiner J, Goodman AD, Gil JA, Daniels AH, Hayda RA. Treatment of femoral neck fractures in patients $45-64$ years of age. Injury. 2019;50(3):708-12.

12. Barışhan FC, Akesen B, Atıc T, Durak K, Bilgen MS. Comparison of hemiarthroplasty and total hip arthroplasty in elderly patients with displaced femoral neck fractures. J Int Med Res. 2018;46(7):2717-30.

13. Boukebous B, Boutroux P, Zahi R, Azmy C, Guillon P. Comparison of dua mobility total hip arthroplasty and bipolar arthroplasty for femoral neck fractures: a retrospective case-control study of 199 hips. Orthop Traumatol Surg Res. 2018;104(3):369-75.
14. Fuchs M, Sass FA, Dietze S, Krämer M, Perka C, Müller M. Cemented hemiarthroplasties are associated with a higher mortality rate after femoral neck fractures in elderly patients. Cementované hemiartroplastiky $u$ zlomenin krčku femuru starších pacientů jsou spojeny s vyšší úmrtností. Acta Chir Orthop Traumatol Cech. 2017;84(5):341-6.

15. Kim YT, Yoo JH, Kim MK, Kim S, Hwang J. Dual mobility hip arthroplasty provides better outcomes compared to hemiarthroplasty for displaced femoral neck fractures: a retrospective comparative clinical study. Int Orthop. 2018;42(6):1241-6.

16. Bartels S, Gjertsen JE, Frihagen F, Rogmark C, Utvåg SE. High failure rate after internal fixation and beneficial outcome after arthroplasty in treatment of displaced femoral neck fractures in patients between 55 and 70 years. Acta Orthop. 2018;89(1):53-8.

17. Wang Z, Bhattacharyya T. Outcomes of hemiarthroplasty and total hip arthroplasty for femoral neck fracture: a Medicare Cohort Study. J Orthop Trauma. 2017;31(5):260-3.

18. Liodakis E, Antoniou J, Zukor DJ, Huk OL, Epure LM, Bergeron SG. Major complications and transfusion rates after hemiarthroplasty and total hip arthroplasty for femoral neck fractures. J Arthroplasty. 2016;31(9):2008-12.

19. Miller CP, Buerba RA, Leslie MP. Preoperative factors and early complications associated with hemiarthroplasty and total hip arthroplasty for displaced femoral neck fractures. Geriatr Orthop Surg Rehabil. 2014;5(2):73-81.

20. Park KS, Oh CS, Yoon TR. Comparison of minimally invasive total hip arthroplasty versus conventional hemiarthroplasty for displaced femoral neck fractures in active elderly patients. Chonnam Med J. 2013;49(2):81-6.

21. Liu YJ, Xu B, Li ZY, Zhang Q, Zhang YZ. Quantitative score system for the surgical decision on adult femoral neck fractures. Orthopedics. 2012;35(2): e137-43.

22. Hedbeck CJ, Enocson A, Lapidus G, Blomfeldt R, Törnkvist H, Ponzer S, et al. Comparison of bipolar hemiarthroplasty with total hip arthroplasty for displaced femoral neck fractures: a concise four-year follow-up of a randomized trial. J Bone Joint Surg Am. 2011;93(5):445-50.

23. Macaulay W, Nellans KW, lorio R, Garvin KL, Healy WL, Rosenwasser MP, et al. Total hip arthroplasty is less painful at 12 months compared with hemiarthroplasty in treatment of displaced femoral neck fracture. HSS J. 2008;4(1):48-54

24. Gebhard JS, Amstutz HC, Zinar DM, Dorey FJ. A comparison of total hip arthroplasty and hemiarthroplasty for treatment of acute fracture of the femoral neck. Clin Orthop Relat Res. 1992;282:123-131.

\section{Publisher's Note}

Springer Nature remains neutral with regard to jurisdictional claims in published maps and institutional affiliations.

Ready to submit your research? Choose BMC and benefit from:

- fast, convenient online submission

- thorough peer review by experienced researchers in your field

- rapid publication on acceptance

- support for research data, including large and complex data types

- gold Open Access which fosters wider collaboration and increased citations

- maximum visibility for your research: over $100 \mathrm{M}$ website views per year

At $\mathrm{BMC}$, research is always in progress.

Learn more biomedcentral.com/submission 